\title{
A Note on Carry Trade and the Related Financial Variables
}

\author{
Takvor H. Mutafoglu \\ Department of Economics, Hunter College, CUNY \\ 695 Park Avenue, New York, NY 10065 \\ Tel: 1-862-703-6923Ｅ-mail: tmutafog@hunter.cuny.edu
}

Received: October 15, 2010

Accepted: November 12, 2010

doi:10.5539/ijef.v3n3p91

\begin{abstract}
A recent study, employing structural vector autoregression (SVAR) methodology, finds that the U.S. stock market performance has a positive impact on the direction of the speculative yen carry trade activity using monthly positioning data of non-commercial traders in currency futures. However, I illustrate that this finding is not robust when weekly positioning data is introduced to the same methodology and sample period. Instead, I find that it is the fluctuations in the Japanese yen against the U.S. dollar exchange rate, rather than the U.S. stock market performance, that determines the direction of the yen carry trade. This represents that conclusions drawn from temporally aggregated data should be interpreted cautiously since temporal aggregation loses information about the underlying data processes.
\end{abstract}

Keywords: Carry trade, Exchange rates, SVAR, Granger causality

\section{Introduction}

A recent article by Nishigaki (2007) investigates the relationship between the yen carry trade activity and the related financial variables in the U.S. and Japan. Carry trade is commonly known as the practice of borrowing money in a currency with low interest rates - "funding currency" - in order to invest in a currency with higher interest rates "target currency". The dynamics of this strategy is relatively straightforward. An investor initiates by borrowing a given amount in a low-interest-rate currency, then converts the funds into a high-interest-rate currency, and finally lends the resulting amount in the target currency at the high interest rate. The yen carry trade has been the focus of the financial markets since the official lending rates has been less than 1 percent for over a decade in Japan. Therefore, investors have been treating the yen as a popular funding currency.

Nishigaki uses the net positions of non-commercial traders in the Japanese currency futures as a measure for the yen carry trade activity. Although, these positions are available at weekly frequency from the U.S. Commodity Futures Trading Commission, Nishigaki chooses to aggregate these weekly positions and use monthly observations in his analysis. His results are threefold. First, he discovers that the interest rate differential between Japan and the U.S. has an insignificant impact on the carry trade activity. Second, he finds that the U.S. stock market performance has a positive impact on the direction of the yen carry trade activity. And lastly, he observes that the speculative carry trade has a significant impact on the nominal exchange rate. Although, his findings are noteworthy, they should be taken with some caution. In this note, I illustrate that while the empirical conclusions drawn from Nishigaki (2007) can be successfully replicated using monthly data, certain findings fail the robustness test when weekly frequency is introduced to the identical model he employs. The organization of the paper is as follows; the next section presents the data and methodology used in Nishigaki (2007), empirical results are discussed in Section 3, and concluding remarks are provided in Section 4.

\section{Data and Methodology}

In order to better understand the effect of financial factors on the speculative yen carry trade activity between the U.S. and Japan, Nishigaki (2007) employs the following variables; the interest rate differential between the U.S. and Japan (IRD), the global volatility indicator $(V I X)$, the dollar against the yen exchange rate (FER), the U.S. stock price (SUS), and the Japanese stock price (SJP). The abbreviations used here are the same as Nishigaki's. The U.S. interest rate is the Federal Funds Target Rate whereas the Japanese interest rate is the Bank of Japan target policy rate which is also known as the Uncollateralized Overnight Call Rate. VIX is the Chicago Board Options Exchange (CBOE) Volatility index. It is an option implied volatility index conveyed by the S\&P 500 stock index option prices and is known as "the fear index" among the market participants. SUS is the S\&P 500 index whereas SJP is the Tokyo Stock Price Index which is also commonly known as the TOPIX. Carry trade activity is measured by the net open positions of non-commercial traders in the yen currency futures market traded on the Chicago Mercantile Exchange (CME). It is abbreviated as IMR and measured as the ratio of long to short contracts in yen currency 
futures. Nishigaki (2007) employs monthly observations of the above mentioned variables from January 1993 to January 2007. We acquire all data from Thomson Datastream except $I M R$ which is calculated from the Commitment of Traders (COT) report provided by the U.S. Commodity Futures Trading Commission (CFTC).

The methodology used in Nishigaki (2007) is structural vector autoregression (SVAR) model. An SVAR representation of the relationship between the six variables can be written as:

$$
B_{0} X_{t}=B(L) X_{t-1}+\varepsilon_{t}
$$

where $X_{t}=$ the column vector $\left(\Delta I R D_{t}, \Delta V I X_{t}, I M R_{t}, \Delta F E R_{t}, \Delta S U S_{t}, \Delta S J P_{t}\right)^{\prime}$

$B_{0}=\mathrm{a} 6 \times 6$ matrix of coefficients, reflecting contemporaneous relationships among the six variables

$\varepsilon_{t}=$ the column vector of structural error terms $\left(\varepsilon_{t}^{I R D}, \varepsilon_{t}^{V I X}, \varepsilon_{t}^{I M R}, \varepsilon_{t}^{F E R}, \varepsilon_{t}^{S U S}, \varepsilon_{t}^{S J P}\right)^{\prime}$

$B(L)=$ a $6 \times 6$ matrix with elements equal to the polynomials $B_{i j}(L)$

$L=$ a lag operator

Pre-multiplying all terms by $B_{0}^{-1}$, we obtain the reduced-form VAR representation:

$$
X_{t}=A(L) X_{t-1}+e_{t}
$$

where $A(L)=B_{o}^{-1} B(L)$ and $e_{t}=B_{0}^{-1} \varepsilon_{t}$

Notice that $B_{0}^{-1}$ represents the matrix of contemporaneous responses of $X_{t}$ to the structural shocks,

$e_{t}=B_{0}^{-1} \varepsilon_{t}$ so $\varepsilon_{t}=B_{o} e_{t}$.

The SVAR utilizes the following expression for the variance-covariance matrix of the reduced-form VAR residuals, denoted by $\Sigma$, in order to identify the elements of $B_{0}^{-1}$.

$$
e_{t}=B_{0}^{-1} \varepsilon_{t} \Rightarrow E e_{t} e_{t}^{\prime}=B_{0}^{-1} E\left(\varepsilon_{t} \varepsilon_{t}^{\prime}\right)\left(B_{0}^{-1}\right) \Rightarrow \Sigma=B_{0}^{-1} \Sigma_{\varepsilon}\left(B_{0}^{-1}\right)^{\prime}
$$

The total number of parameters to be estimated is 93. The right-hand side of equation (3) has 72 unknown parameters. However, 57 contemporaneous restrictions are provided by the assumed orthogonality of the shocks, normalization of the diagonal elements of $B_{0}^{-1}$ to equal unity, combined with the estimated variance-covariance matrix of the reduced-form $\operatorname{VAR}\left(\Sigma_{e}\right)$, leaves 15 restrictions for exact identification of the unknown parameters.

Therefore, to identify the structural shocks from the reduced-form shocks, a number of restrictions have been imposed.

1. Shocks to other variables in the system have no effects on the interest rate differential between the US and Japan. Thus, $I R D$ is to be the most exogenous variable in the system. This assumption leads to the restrictions $b_{12}(L)=b_{13}(L)=b_{14}(L)=b_{15}(L)=b_{16}(L)=0$.

2. Chicago Board Options Exchange (CBOE) Volatility Index, $V I X$, is assumed to be affected only by shocks to IRD. This restriction is incorporated as $b_{23}(L)=b_{24}(L)=b_{25}(L)=b_{26}(L)=0$.

3. Currency carry trade proxy $I M R$ is influenced by shocks to $I R D$, and $V I X$, which yields the restrictions $b_{34}(L)=b_{35}(L)=b_{36}(L)=0$.

4. S\&P 500 stock index, SUS, and Tokyo Stock Price Index, SJP, have no contemporaneous effect on the dollar against yen exchange rate, FER. This assumption is illustrated as $b_{45}(L)=b_{46}(L)=0$.

5. SUS is assumed to be affected by shocks to IRD, VIX,IMR, and FER. This restriction is introduced as $b_{56}(L)=0$.

6. Shocks to all other variables are assumed to affect Tokyo Stock Price Index, SJP, and hence it is determined endogenously in the system.

With the above mentioned 15 restrictions, the system is exactly identified. The system of equations arising from these restrictions can be expressed as follows:

$$
\begin{aligned}
& \Delta I R D_{t}=b_{11} u_{t}^{I R D} \\
& \Delta V I X_{t}=b_{21} u_{t}^{I R D}+b_{22} u_{t}^{V I X} \\
& I M R_{t}=b_{31} u_{t}^{I R D}+b_{32} u_{t}^{V I X}+b_{33} u_{t}^{I M R} \\
& \Delta F E R_{t}=b_{41} u_{t}^{I R D}+b_{42} u_{t}^{V I X}+b_{43} u_{t}^{I M R}+b_{44} u_{t}^{F E R} \\
& \Delta S U S_{t}=b_{51} u_{t}^{I R D}+b_{52} u_{t}^{V I X}+b_{53} u_{t}^{I M R}+b_{54} u_{t}^{F E R}+b_{55} u_{t}^{S U S} \\
& \Delta S J P_{t}=b_{61} u_{t}^{I R D}+b_{62} u_{t}^{V I X}+b_{63} u_{t}^{I M R}+b_{64} u_{t}^{F E R}+b_{65} u_{t}^{S U S}+b_{66} u_{t}^{S J P}
\end{aligned}
$$


Although, a detailed theoretical reasoning of the above deemed ordering is not included here, it could be found at Nishigaki (2007).

Both the Augmented Dickey-Fuller (ADF) and Phillip-Perron (PP) tests indicate that all the variables are integrated of order 1 except $I M R$. Therefore, all the variables are introduced to the system in first differences, denoted by $\Delta$, except for $I M R$. Also, all the variables, except $I R D$, are entered into natural logarithms.

\section{Empirical Results}

Our attempt to replicate Nishigaki (2007) findings based on monthly observations is met with success. Through impulse response functions, variance decompositions and VAR Granger causality test, we were able to observe his key conclusions such as the insignificant effect of the interest rate differential between the U.S. and Japan on the yen carry trade, the dominant and positive impact of the U.S. stock market performance on the carry trade activity, and finally the significant impact of the speculative yen carry trade on the nominal exchange rate.

We set out to test the robustness of these results by changing the frequency of the data used in the SVAR representation. The COT report is calculated from Wednesday to Tuesday and released to the public the following Friday by the CFTC. Since net positions now represent the outcome of weekly adjustments of trading strategies by the traders, the rest of the variables in the system are averaged over the Wednesday-Tuesday interval to match the COT data. Although, the option to expand the sample period exists, we chose not to do so due to the recently experienced financial crisis which had created significant instability in the markets. Therefore, the sample period remains from January 1993 to January 2007. Furthermore, we did not alter the above mentioned ordering in the SVAR system. Once again all the variables are tested for unit root using the ADF and PP tests and the results are reported at Table 1. As before, all the variables are found to be I(1) at the 1 percent significance level except for $I M R$ which is integrated of $\mathrm{I}(0)$. Therefore, all the variables are first differenced except the $I M R$.

First, we study the impulse response functions. Figure 1 displays the response of $I M R$ to a one-standard deviation innovation of a particular shock on all the variables over a 20 -week period range and contains \pm 2 standard error bands. Our results indicate that the only variable which has a significant impact on the behavior of the speculative carry trade activity is the nominal exchange rate. Specifically, we observe that when the Japanese yen depreciates against the U.S. dollar, the yen carry trade raises. None of the other variables seem to have a significant effect on the speculative yen carry trade activity. Note that while Nishigaki (2007) observes that a positive shock in the S\&P 500 index leads to an increase in the yen carry trade activity, here we observe the opposite: that is, when a positive shock is introduced to the U.S. stock price, yen carry trade activity decreases. Therefore, we fail to validate his eminent finding. Nevertheless, when we look at Figure 2, which reveals the impulse responses of all the variables to IMR shocks, we still do see the statistically significant impact of a sudden reversal of carry trade positions on the nominal dollar against the yen exchange rate. We observe that the Japanese yen will appreciate against the U.S. dollar when investors unwind their positions. This finding is consistent with Nishigaki's.

Table 2 reports the variance decompositions. The variance decomposition of IMR suggest that shocks to the dollar against the yen exchange rate explain more than 4 percent of the variance in $I M R$ six weeks after a shock and in fact the explanatory power of shocks to FER increases to 5.38 percent after 20 weeks. On the other hand, evidence suggests that the U.S. stock price has no impact on the variance of the yen carry trade activity. However, we continue to see the ability of investors' carry trade positions to influence the dollar against the yen exchange rate. Table 2 displays that a shock to IMR explains about 15 percent of the variance in FER.

We perform a multivariate version of the Granger causality test because Granger causality test is of limited usefulness in a VAR system. This test is also known as a block-exogeneity test. Block-exogeneity tests generalize Granger causality, indicating whether the lagged independent variables jointly affect a particular dependent variable. Table 3 provides the VAR Granger causality test results. The null hypothesis is that the coefficients are zero, no Granger causality, and a significantly low p-value indicates a rejection of the null. According to the table, we observe that only the changes in the nominal dollar against the yen exchange rate, $F E R$, significantly Granger-causes the non-commercial positions, IMR. None of the other variables have any causal effect on the speculative yen carry trade activity. This finding is in total contradiction with the findings of Nishigaki (2007). It illustrates that the most important variable to influence the direction of the carry trade activity is the exchange rate fluctuations in the market.

\section{Conclusion}

In this note, we tested the robustness of the results obtained by Nishigaki (2007). We conclude that his key finding, which is the dominant impact of the U.S. stock market performance on the direction of the yen carry trade activity, cannot be observed when weekly, rather than monthly, observations are used. Instead, we observe the significant 
impact of the nominal dollar against the yen exchange rate on the speculative yen carry trade activity. We find that when the Japanese yen depreciates against the U.S. dollar, the yen carry trade raises. The outcome of the Granger causality test confirms our findings. Perhaps, one reason why Nishigaki's finding is not robust to using higher frequency data has to do with temporal aggregation. It is known that aggregating data from higher to lower frequencies, as Nishigaki implicitly does, can imply some risks. For instance, Rossana and Seater (1995) and Marcellino (1999) have empirically shown that temporal aggregation causes a severe loss of information about the time series processes driving many economic variables. Therefore, one must be cautious while interpreting results based on temporally aggregated data since temporal aggregation loses information about the underlying data processes.

\section{References}

Marcellion, M. (1999).Some Consequences of Temporal Aggregation in Empirical Analysis.Journal of Business and Economic Statistics 17, No.1, 129-136.

Nishigaki, H. (2007). Relationship between the Yen Carry Trade and the Related Financial Variables. Economics Bulletin 13, No.2, 1-7.

Rossana, R. and J. Seater. (1995). Temporal Aggregation and Economic Time Series.Journal of Business and Economic Statistics 13, No.4, 441-451.

Table 1. Unit Root Tests

\begin{tabular}{|c|c|c|c|c|c|}
\hline & & ADF & $\mathbf{P P}$ & ADF & PP \\
\hline Variable & & \multicolumn{2}{|c|}{ Intercept } & \multicolumn{2}{|c|}{ Intercept and Trend } \\
\hline \multirow{2}{*}{ IRD } & Level & -1.91 & -1.89 & -2.03 & -1.98 \\
\hline & First Difference & $-27.19 * * *$ & $-28.40 * * *$ & $-27.24 * * *$ & $-28.39 * * *$ \\
\hline \multirow{2}{*}{$\ln (\mathrm{VIX})$} & Level & $-3.00 * *$ & $-2.99 * *$ & -2.93 & -2.93 \\
\hline & First Difference & $-34.21 * * *$ & $-41.38 * * *$ & $-34.21 * * *$ & $-42.29 * * *$ \\
\hline \multirow{2}{*}{$\ln (\mathrm{IMR})$} & Level & $-6.19^{* * *}$ & $-6.16^{* * *}$ & $-6.34 * * *$ & $-6.34 * * *$ \\
\hline & First Difference & $-18.40 * * *$ & $-32.08 * * *$ & $-18.39 * * *$ & $-32.03 * * *$ \\
\hline \multirow{2}{*}{$\ln ($ FER $)$} & Level & -2.30 & -2.39 & -2.59 & -2.68 \\
\hline & First Difference & $-26.53 * * *$ & $-26.53 * * *$ & $-26.52 * * *$ & $-26.52 * * *$ \\
\hline \multirow{2}{*}{$\ln (\mathrm{SUS})$} & Level & -1.59 & -1.55 & -1.26 & -1.26 \\
\hline & First Difference & $-31.22 * * *$ & $-31.24 * * *$ & $-31.24 * * *$ & $-31.26 * * *$ \\
\hline \multirow{2}{*}{$\ln (\mathbf{S J P})$} & Level & -1.58 & -1.61 & -1.47 & -1.51 \\
\hline & First Difference & $-27.30 * * *$ & $-27.30 * * *$ & $-27.29 * * *$ & $-27.29 * * *$ \\
\hline
\end{tabular}

Note: The lags in the tests were estimated through the Schwartz Information Criterion. $* * * \mathrm{H}_{0}$ of a unit root is rejected at the $1 \%$, $* * 5 \%$, and $* 10 \%$ level.IRD is the interest rate differential between the U.S. and Japan, VIX is the CBOE volatility index, IMR is the ratio of long to short positions in JPY futures, FER is the Japanese yen per U.S. dollar, SUS is the S\&P 500 stock index, and SJP is Tokyo stock price index. 
Table 2. Variance Decompositions

\begin{tabular}{|c|c|c|c|c|c|c|c|}
\hline $\begin{array}{c}\text { Explained } \\
\text { Variable } \\
\end{array}$ & $\begin{array}{c}\text { Horizon } \\
\text { (weeks) }\end{array}$ & D(IRD) & D(VIX) & IMR & D(FER) & D(SUS) & D(SJP) \\
\hline \multirow{4}{*}{ D(IRD) } & 1 & 100.000 & 0.000 & 0.000 & 0.000 & 0.000 & 0.000 \\
\hline & 6 & 99.258 & 0.043 & 0.090 & 0.007 & 0.120 & 0.479 \\
\hline & 12 & 99.243 & 0.043 & 0.105 & 0.008 & 0.120 & 0.479 \\
\hline & 20 & 99.238 & 0.043 & 0.109 & 0.009 & 0.120 & 0.479 \\
\hline \multirow{4}{*}{ D(VIX) } & 1 & 0.001 & 99.998 & 0.000 & 0.000 & 0.000 & 0.000 \\
\hline & 6 & 0.370 & 98.128 & 0.149 & 0.427 & 0.907 & 0.018 \\
\hline & 12 & 0.370 & 98.127 & 0.149 & 0.427 & 0.907 & 0.018 \\
\hline & 20 & 0.370 & 98.127 & 0.149 & 0.427 & 0.907 & 0.018 \\
\hline \multirow{4}{*}{ IMR } & 1 & 0.082 & 0.125 & 99.792 & 0.000 & 0.000 & 0.000 \\
\hline & 6 & 0.051 & 0.184 & 94.556 & 4.763 & 0.251 & 0.191 \\
\hline & 12 & 0.054 & 0.193 & 93.979 & 5.273 & 0.301 & 0.197 \\
\hline & 20 & 0.054 & 0.195 & 93.850 & 5.386 & 0.313 & 0.198 \\
\hline \multirow{4}{*}{ D(FER) } & 1 & 0.018 & 0.004 & 15.494 & 84.481 & 0.000 & 0.000 \\
\hline & 6 & 0.675 & 0.082 & 15.483 & 83.282 & 0.392 & 0.084 \\
\hline & 12 & 0.674 & 0.082 & 15.555 & 83.211 & 0.392 & 0.084 \\
\hline & 20 & 0.674 & 0.082 & 15.577 & 83.182 & 0.392 & 0.084 \\
\hline \multirow{4}{*}{ D(SUS) } & 1 & 0.192 & 51.618 & 0.023 & 0.016 & 48.148 & 0.000 \\
\hline & 6 & 0.907 & 50.998 & 0.068 & 0.216 & 47.670 & 0.139 \\
\hline & 12 & 0.906 & 50.989 & 0.084 & 0.217 & 47.661 & 0.139 \\
\hline & 20 & 0.906 & 50.986 & 0.089 & 0.217 & 47.659 & 0.139 \\
\hline \multirow{4}{*}{ D(SJP) } & 1 & 0.002 & 10.608 & 0.047 & 0.023 & 6.384 & 82.932 \\
\hline & 6 & 0.339 & 10.480 & 0.401 & 0.040 & 6.352 & 82.386 \\
\hline & 12 & 0.339 & 10.475 & 0.448 & 0.044 & 6.349 & 82.344 \\
\hline & 20 & 0.339 & 10.473 & 0.462 & 0.045 & 6.348 & 82.331 \\
\hline
\end{tabular}

Note: The table reports the forecast error variance decompositions which indicate the amount of information each column variable contribute to the row variables.

Table 3. VAR Granger Causality Test (P-values)

\begin{tabular}{c|cccccc}
\hline & D(IRD) & D(VIX) & IMR & D(FER) & D(SUS) & D(SJP) \\
\hline D(IRD) & & 0.2903 & 0.9703 & 0.1122 & 0.1131 & 0.2887 \\
D(VIX) & 0.5857 & & 0.8897 & 0.8084 & 0.7533 & 0.8966 \\
IMR & 0.6311 & 0.8947 & & 0.3348 & 0.7020 & 0.1839 \\
D(FER) & 0.9614 & 0.1846 & 0.0000 & & 0.5009 & 0.8949 \\
D(SUS) & 0.8870 & 0.0281 & 0.8408 & 0.2005 & & 0.9236 \\
D(SJP) & 0.1782 & 0.9707 & 0.1899 & 0.6707 & 0.6873 & \\
\hline
\end{tabular}

Note: Table shows the marginal probabilities associated with the Granger-causality test. The format is such that the rows reflect the Granger-causal impact of the row-variable on the column-variable. 
Accumulated Response to Structual One S.D. Innovations \pm 2 S.E. Accumulated Response of IMR to D(IRD)

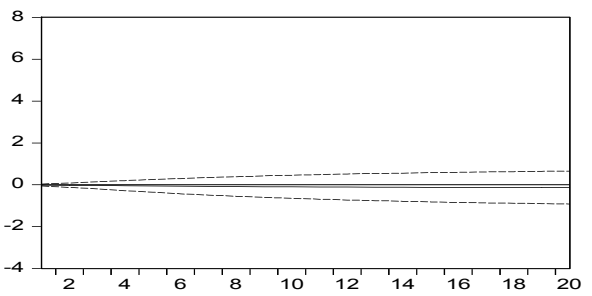

Accumulated Response of IMR to D(VIX)

Accumulated Response of IMR to IMR

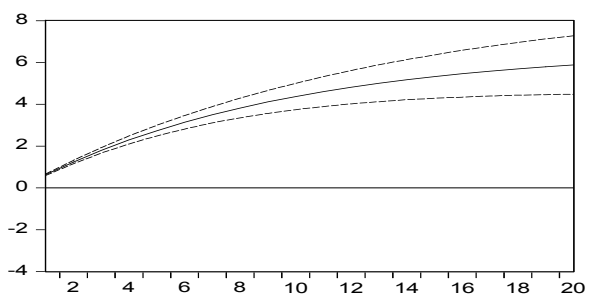

Accumulated Response of IMR to D(FER)

Accumulated Response of IMR to D(SUS)
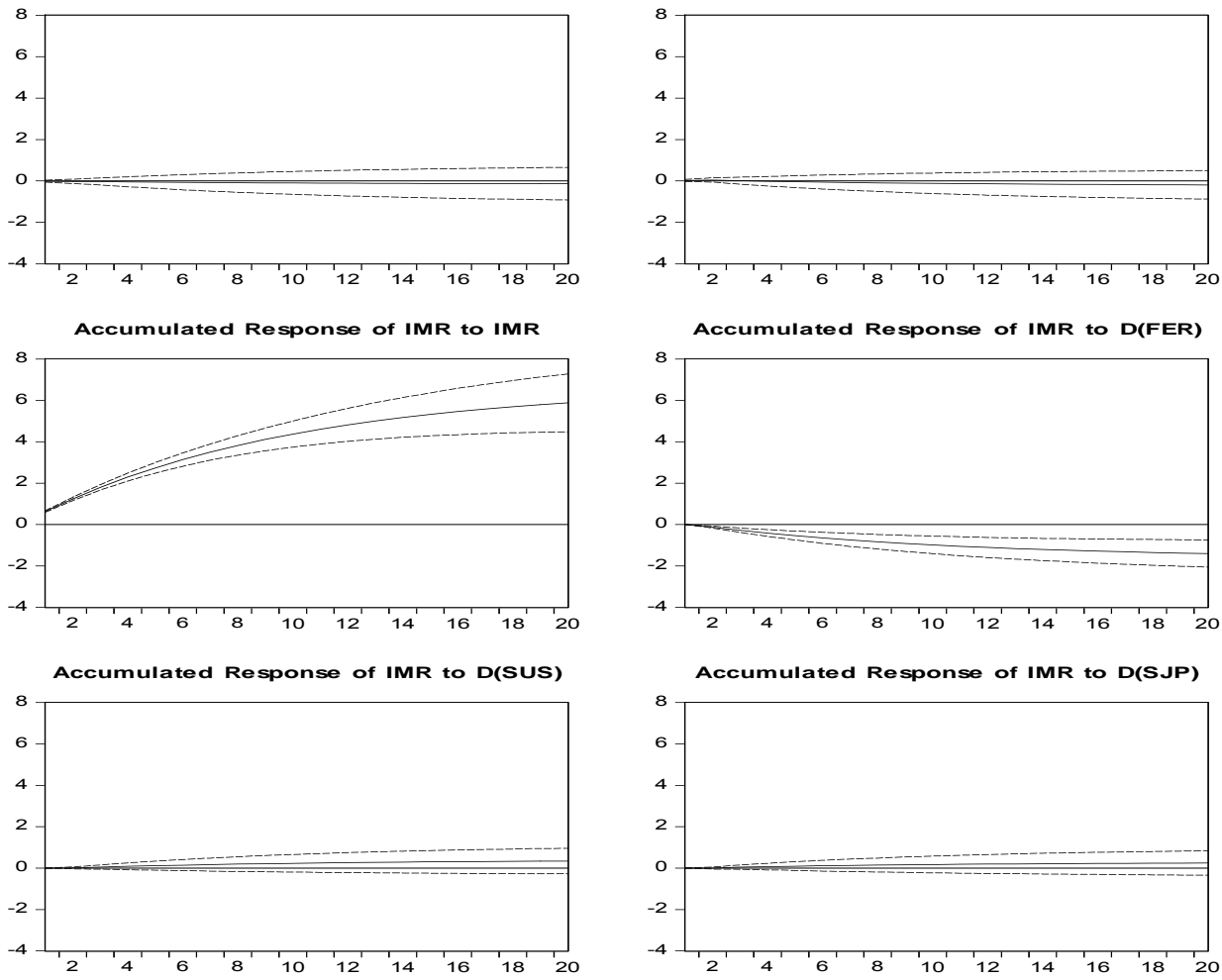

Accumulated Response of IMR to D(SJP)

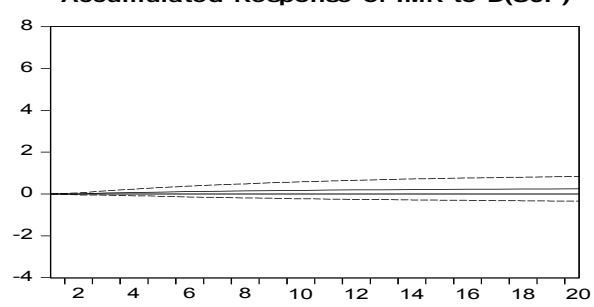

Figure 1. Impulse Responses of IMR

Accumulated Response to Structural One S.D. Innovations \pm 2 S.E. Accumulated Response of D(IRD) to IMR

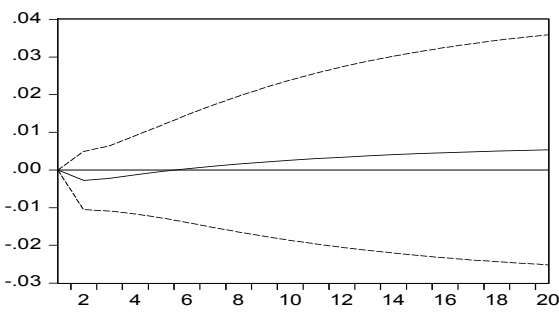

Accumulated Response of D(VIX) to IMR

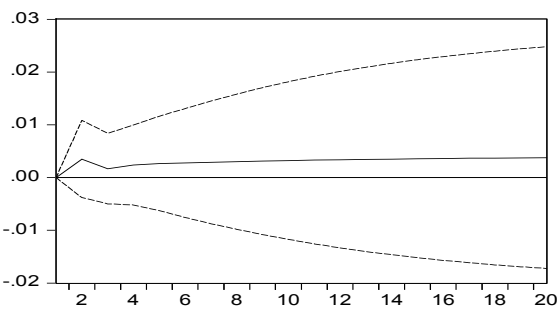

Accumulated Response of IMR to IMR

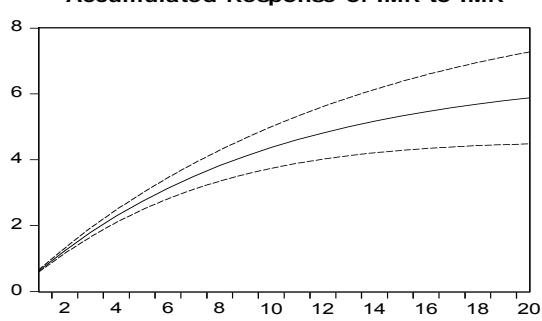

Accumulated Response of D(FER) to IMR

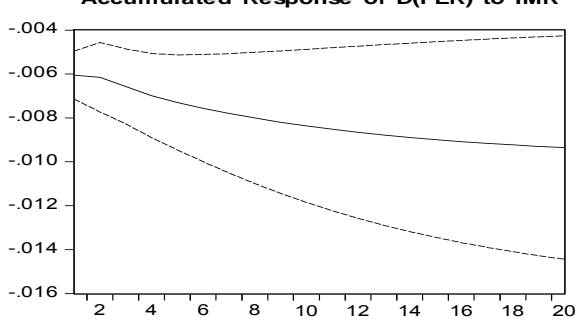

Accumulated Response of D(SUS) to IMR

Accumulated Response of D(SJP) to IMR
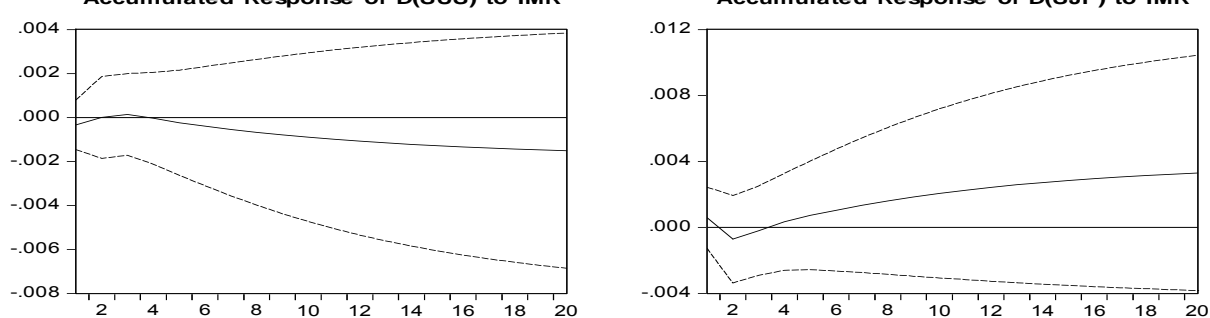

Figure 2. Impulse Responses to IMR 